\title{
Finite Element Analysis of a Three Speed Induction Machine
}

\author{
L. Melcescu ${ }^{1}$, T. Tudorache ${ }^{1}$ and M. Popescu ${ }^{2}$ \\ ${ }^{1}$ University POLITEHNICA of Bucharest, Electrical Engineering Faculty, MMAE Dept., \\ 313 Splaiul Independentei, 060042, Sect. 6, Bucharest (Romania), \\ Phone/Fax number: +0040 21 4029171, e-mail: leonard@amotion.pub.ro,tudorach@amotion.pub.ro \\ ${ }^{2}$ National Institute for R\&D in Electrical Engineering (ICPE-CA), \\ 313 Splaiul Unirii, 030138, Sect. 3, Bucharest (Romania), \\ Phone number: +0040 21 3467231, e-mail: pd_mihail@yahoo.com
}

\begin{abstract}
This paper deals with the Finite Element (FE) analysis of a special Three Speed Squirrel Cage Induction Machine (TSSCIM) with pole changing stator windings. Compared to classical multi-speed induction machines, the studied TSSCIM is designed so as to change in the same time the number of pole pairs $(p)$ and the number of stator phases $(m)$ so as to keep constant the product $p \times m$.
\end{abstract}

The numerical model of the machine used in this study is based on a 2D plane-parallel finite element approach and aims at finding some of the main steady state operation characteristics of the machine working both as motor and generator for three different running speeds.

A comparison of the proposed TSSCIM with a classical inverter fed squirrel cage induction machine is also presented in order to underline some advantages and disadvantages of each solution.

\section{Key words}

Finite element analysis, three speed induction machine, steady state characteristics and transient response.

\section{Introduction}

Multi-speed squirrel cage induction machines can be used without inverters in several types of cheap and unpretentious electrical drives systems where the machine speed may be changed in steps such as: fans, pumps, drilling machines, food processing machines, etc. [1]-[2].

An important advantage of this type of machines working as motor is represented by the possibility to obtain different speed ranges only by changing the connexions of the stator windings without using frequency converters [1].

The speed increase beyond the rated value for a classical inverter fed induction motor supposes typically the increase of the inverter output frequency that means higher iron losses and a poorer efficiency of the machine [3]. A multi speed induction machine allows also a speed increase but at the utility frequency, limiting thus the growth of the iron losses.

The Three-Speed Squirrel Cage Induction Machine (TSSCIM) studied in the paper has a changing number of phases $(m)$ that modifies simultaneously with the number of pole pairs $(p)$ so as the product $p \times m=c t$. [4].

An expected advantage of the studied TSSCIM working as motor consists not only in the possibility to change the machine speed steps using the same stator windings but also to increase the electromagnetic torque reserve for small speeds range. Such features can be very useful in particular applications such electric vehicles, where the electronic controlled TSSCIM could replace the classical engine and its gearbox.

The utilization of the proposed TSSCIM for wind turbines could be also possible, as a solution to harness more energy from the wind than a classical single speed induction generator [5].

\section{Short Description of the Studied Machine}

The main data of the studied TSSCIM are briefly presented in Table I for the three numbers of pole pairs $(p)$ and phases $(m)$. We can notice that the product $m \times p$ is kept constant (i.e. $m_{1} \times p_{1}=3 \times 4=m_{2} \times p_{2}=6 \times 2=$ $m_{3} \times p_{3}=12 \times 1=12$ ).

Table I. - Main data of the studied machine

\begin{tabular}{|l|c|}
\hline Rated power at 750 rpm $[\mathrm{kW}]$ & 1.1 \\
\hline Rated voltage $[\mathrm{V}]$ & 400 \\
\hline No. of stator slots & 24 \\
\hline No. or rotor bars & 33 \\
\hline No. of phases $\left(\mathrm{m}_{1} / \mathrm{m}_{2} / \mathrm{m}_{3}\right)$ & $3 / 6 / 12$ \\
\hline No. of pole pairs $\left(\mathrm{p}_{1} / \mathrm{p}_{2} / \mathrm{p}_{3}\right)$ & $4 / 2 / 1$ \\
\hline Synchronous speed $\left(\mathrm{n}_{1} / \mathrm{n}_{2} / \mathrm{n}_{3}\right)[\mathrm{rpm}]$ & $750 / 1500 / 3000$ \\
\hline
\end{tabular}


The exterior diameter of the magnetic circuit is $150 \mathrm{~mm}$, the stator bore diameter is $103 \mathrm{~mm}$ and the axial machine length is $130 \mathrm{~mm}$.

The poly-phase induction machine is usually associated with an inverter, Fig. 1a). The stator winding is designed so as the modification of the number of phases and poles to be done by the control of the phase-shift angle between the currents flowing through the 12 coils. In case of $2 p=8$ machine there are 3 groups of 4 coils parallel connected. The currents flowing through 2 coils placed in different groups are electrically phase-shifted with $120^{\circ}$, Fig. 1b). For $2 p=4$ machine each of the 6 groups of coils has 2 coils with identical currents flowing through them. In this case between the currents flowing through two coils placed in two successive groups there is a phase-shift angle of $60^{\circ}$, Fig. 1c). To operate the machine with $2 p=2$ the currents flowing through 2 successive coils are phase-shifted with $30^{\circ}$, Fig. 1d).

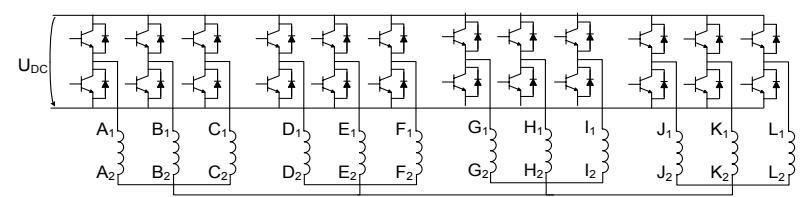

a)

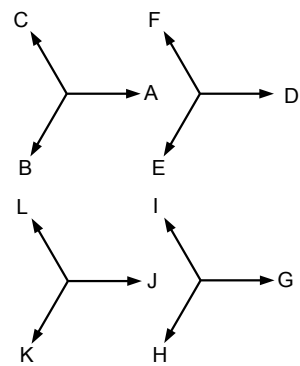

b)

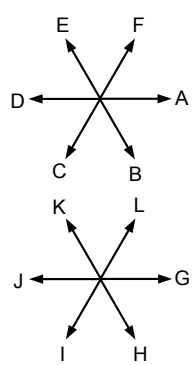

c)

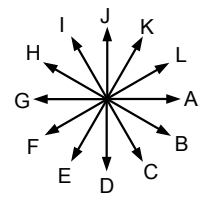

d)
Fig. 1. Example of poly-phase inverter used to control the TSSCIM.

A cross-section through the studied TSSCIM is shown in Fig. 2 where we can identify the stator and rotor geometry of the machine and the mesh of the 2D computation domain (with a detail in the air-gap region).

\section{FE 2D Model of the Machine}

The FE 2D analysis of the steady state characteristics of the studied machine is based on the following partial differential equation derived from Maxwell's equations [6]:

$$
\operatorname{curl}[(1 / \mu) \operatorname{curl} \mathbf{A}]=\mathbf{J}_{\mathbf{s}}-\mathbf{j} \sigma \omega \mathbf{A},
$$

where $\mathbf{A}$ is the magnetic vector potential, $\mu$ is the magnetic permeability, $\mathbf{J}_{\mathbf{s}}$ is the current density (apriori unknown) flowing through the stator windings, $\sigma$ is the electric conductivity of solid conductors (i.e. rotor bars in our case), $\omega$ is the pulsation of supply voltage. The boundary conditions imposed on the external frontier of the stator region is of tangential magnetic field type (i.e. $\mathbf{B} \cdot \mathbf{n}=0$ ).

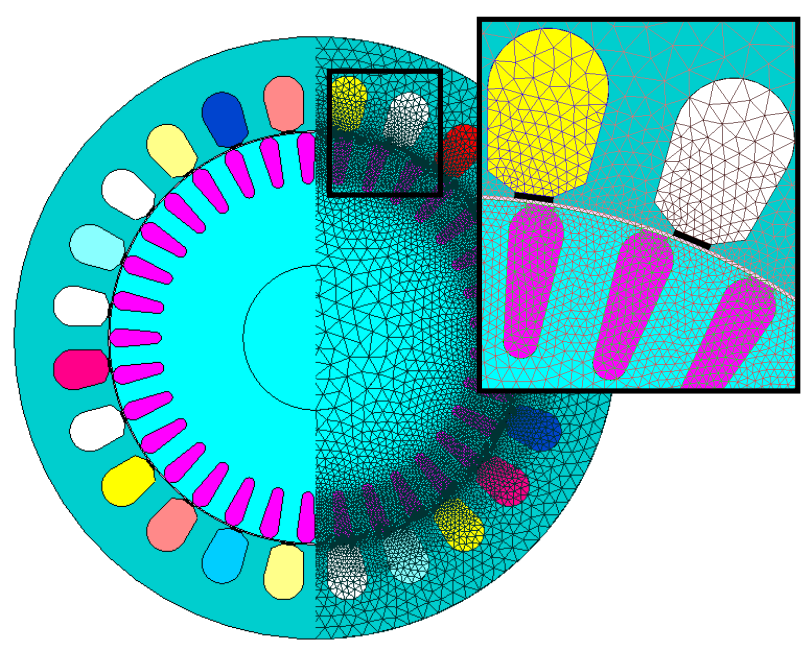

Fig. 2. Cross-section through the studied machine. Computation domain for the FE 2D analysis problem and FE mesh.

The stator and rotor magnetic cores are made of electric steel laminations of M600-50A, the machine shaft is made of common steel and the rotor cage is made of aluminum.

Since the current density $\mathbf{J}_{\mathbf{s}}$ in (1) is not apriori known, the steady-state field model is coupled to the circuit model of the machine, Fig. 3. The rotor cage is modeled by a special macro-circuit implemented in the Flux software package [6]. The resistances connected across the stator coils are used to model the iron losses in the stator core. The rotor core losses are neglected.

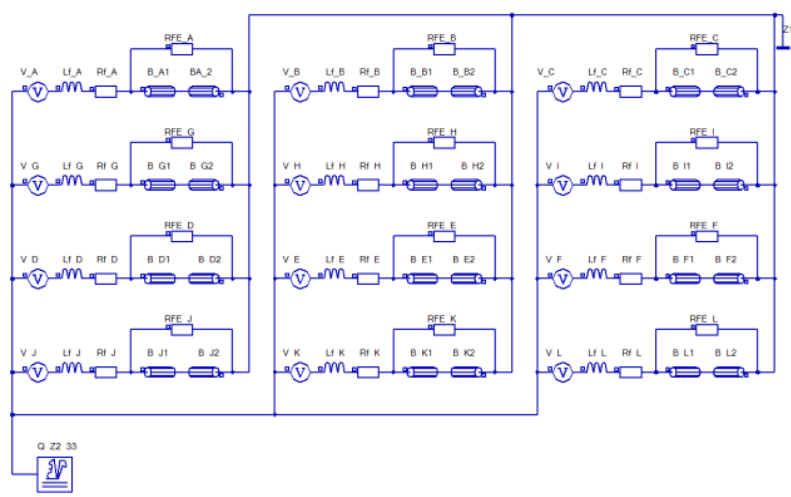

Fig. 3. Circuit model of the machine.

The circuit diagram shown in Fig. 3 allows the modification of phase and pole number by changing the initial phases of the voltage sources.

\section{Numerical Results}

By solving the steady state AC problem associated to the TSSCIM when operating as a 2,4 or 8 pole motor at rated load, we obtained the magnetic field lines and magnetic flux density charts shown in Fig. 4.

This study is based on a three-phase machine initially rated at $1.1 \mathrm{~kW}$ with 8 poles (4 pole pairs) that was slightly redesigned so as to make the magnetic circuit well adapted for all the considered poles numbers. 


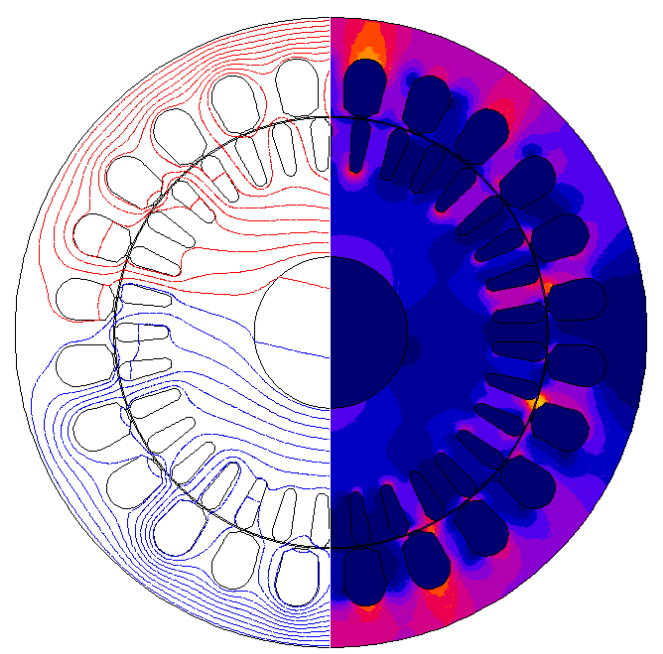

a)

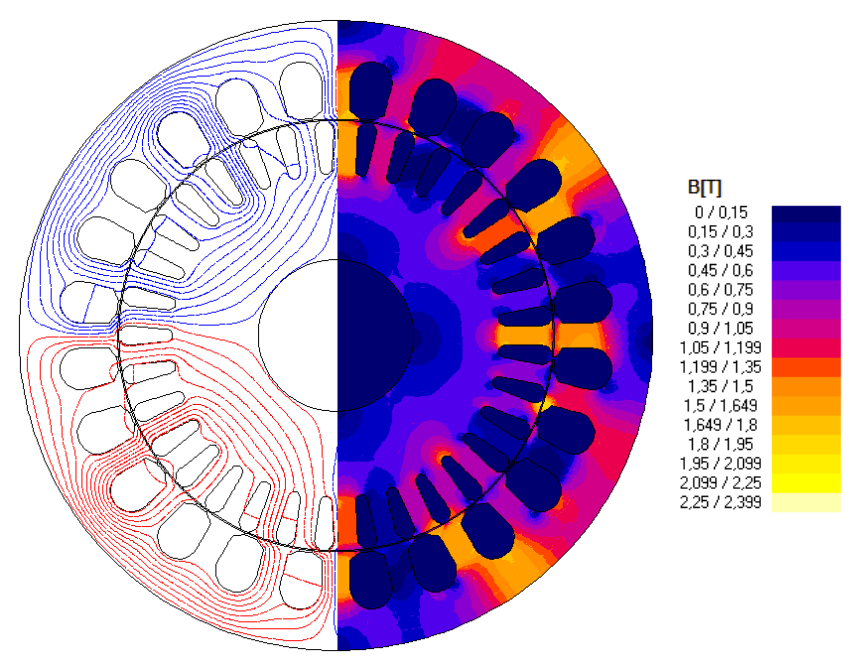

b)

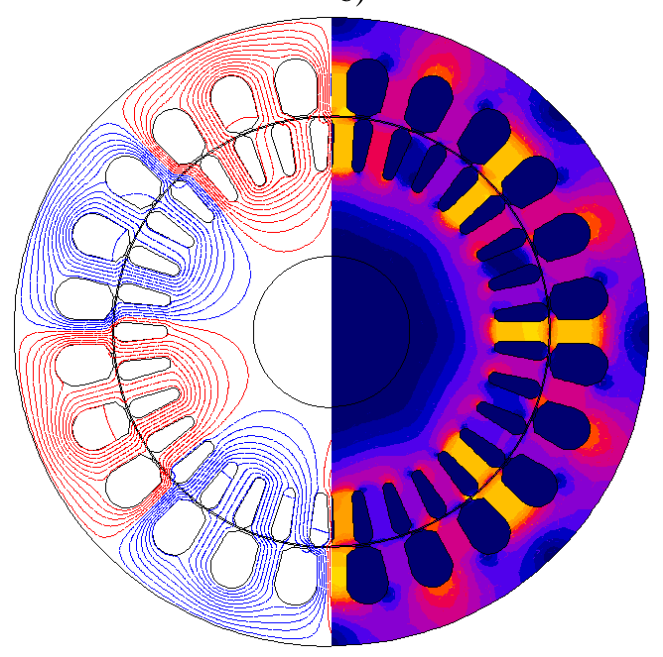

c)

Fig. 4. Magnetic field lines and magnetic flux density chart of TSSCIM at rated load in motor regime; a) 2 pole machine; b) 4 pole machine; c) 8 pole machine.

It is known that in case of 2 pole machines all the resulting magnetic flux produced by the stator/rotor currents passes through the stator/rotor magnetic yokes. Thus the width of magnetic yokes should be large enough to avoid high magnetic saturation in those regions. On the contrary in

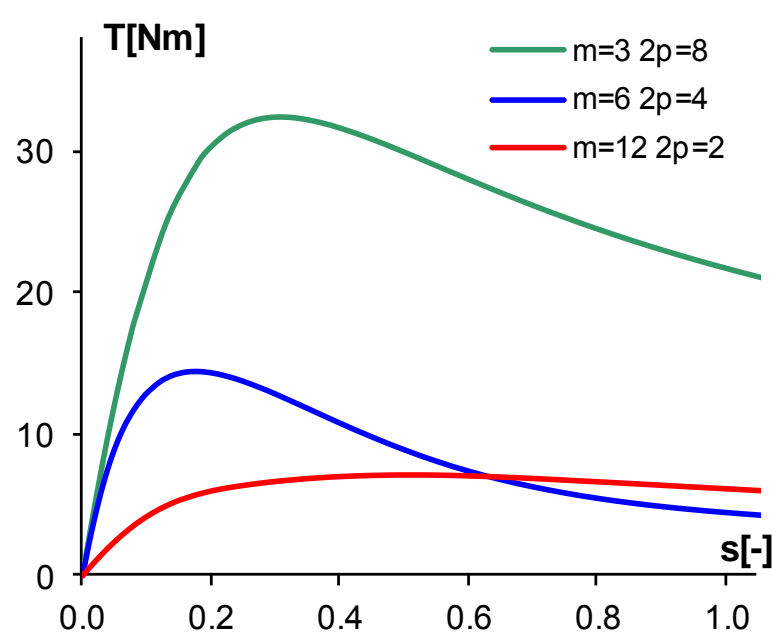

Fig. 5. Torque-slip characteristics of the TSSCIM for various no. of poles/phases, operating as motor.

case of electrical machines with several pole pairs the magnetic flux per pole stresses the stator/rotor teeth and their size should be chosen properly to limit their magnetic saturation.

By studying the results in Fig. 4, we can notice that the average magnetic flux density values in the teeth region and in the stator/rotor yokes regions are acceptable for all the three studied machines. We can remark also that in case of $2 p=8$ the teeth are more saturated and the yoke less. Even though in case of $2 p=4$ the area of a magnetic pole increases both the teeth and the yoke are magnetically stressed, Fig. 4b), because the winding factor in this case is $k_{\mathrm{w}_{-} 4}=0.707$ compared to $k_{\mathrm{w}_{-} 8}=1$ for $2 \mathrm{p}=8$. In case of $2 \mathrm{p}=2$, the winding factor is $k_{\mathrm{w}_{-} 2}=0.77$, but the increase of the magnetic pole area entails a decrease of the saturation level.

By solving (1) for different slip values we obtained the torque slip characteristics for the three studied combinations of poles/phases, in case of motor operation Fig. 5.

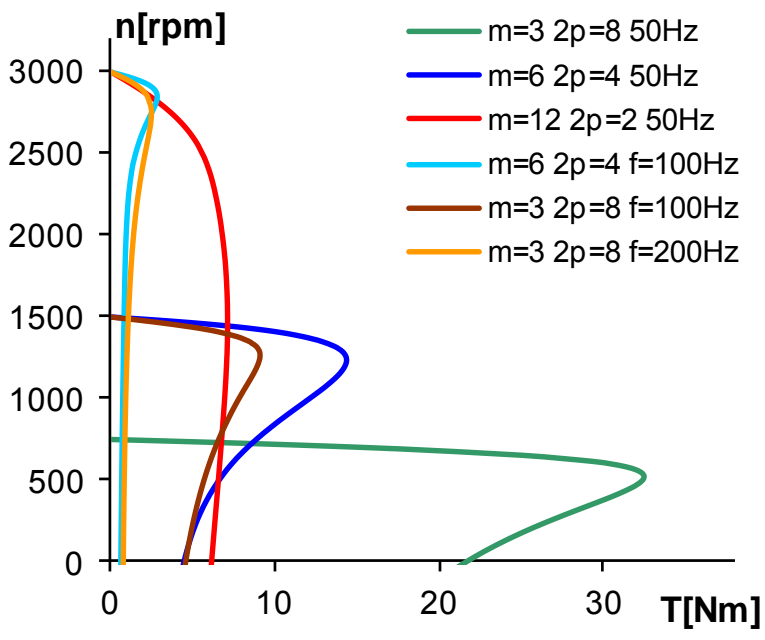

Fig. 6. Speed-torque characteristics of the TSSCIM for various no. of poles/phases, operating as motor. 
Table II. - Electromagnetic torque and output power at rated current for different configuration and frequency

\begin{tabular}{|c|c|c|c|c|c|c|}
\hline Case & $\begin{array}{c}\mathrm{m}=3 \\
2 \mathrm{p}=8 \\
\mathrm{f}=50 \mathrm{~Hz}\end{array}$ & $\begin{array}{c}\mathrm{m}=6 \\
2 \mathrm{p}=4 \\
\mathrm{f}=50 \mathrm{~Hz}\end{array}$ & $\begin{array}{c}\mathrm{m}=3 \\
2 \mathrm{p}=8 \\
\mathrm{f}=100 \mathrm{~Hz}\end{array}$ & $\begin{array}{c}\mathrm{m}=12 \\
2 \mathrm{p}=2 \\
\mathrm{f}=50 \mathrm{~Hz}\end{array}$ & $\begin{array}{c}\mathrm{m}=6 \\
2 \mathrm{p}=4 \\
\mathrm{f}=100 \mathrm{~Hz}\end{array}$ & $\begin{array}{c}\mathrm{m}=3 \\
2 \mathrm{p}=8 \\
\mathrm{f}=200 \mathrm{~Hz}\end{array}$ \\
\hline $\begin{array}{c}\mathrm{T}_{\mathrm{n}} \\
{[\mathrm{Nm}]}\end{array}$ & 15.2 & 9.9 & 8.64 & 5.5 & 2.4 & 2.18 \\
\hline $\mathrm{P}_{2}[\mathrm{~kW}]$ & 1.1 & 1.95 & 1.75 & 2.13 & 1.14 & 0.49 \\
\hline
\end{tabular}

The speed versus torque characteristics of the studied machines is shown in Fig. 6. The results in Figs. 5 and 6 emphasize that the pull-out torque increases with the number of poles while the motor speed for a given load torque decreases. Such torque-slip (or speed-torque) characteristics are interesting for electric traction systems, since they allow an easy vehicle speed changing by modifying the number of poles/phases of the same electric motor in three steps. The fine tuning of the vehicle speed can be ensured by the proper control of the frequency of the inverter that supplies the motor. Such electric drive system is reliable and it could replace the classical engine and the corresponding gearbox of a vehicle.

Fig. 6 includes also the curves obtained for the operation of 4 and 8 pole machines supplied at frequency values higher than the rated one $(100 \mathrm{~Hz}$ and $200 \mathrm{~Hz})$. At small speeds and high torques, the machine can operates with 8 poles. The speed increase is done by changing the inverter frequency until the motor reaches a zone covered by the 4 pole machine. A reduction of pull-out torque of about 4 times is obtained by doubling the supply frequency and only of about 2 times by doubling the number of phases. A similar situation can be noticed if we compare the 4 pole machine supplied at $100 \mathrm{~Hz}$ with the 2 pole machine supplied at $50 \mathrm{~Hz}$.

In Table II are presented the values of the electromagnetic torque and output power corresponding to the rated current for each of the curves in Fig. 6. For a speed of about $1500 \mathrm{rpm}$ the output torque of the 4 pole machine supplied at $50 \mathrm{~Hz}$ is with $14.5 \%$ higher than the torque of the 8 pole machine at $100 \mathrm{~Hz}$. The 2 pole motor at $50 \mathrm{~Hz}$ develops a torque with $129 \%$ higher than the 4 pole motor at $100 \mathrm{~Hz}$.

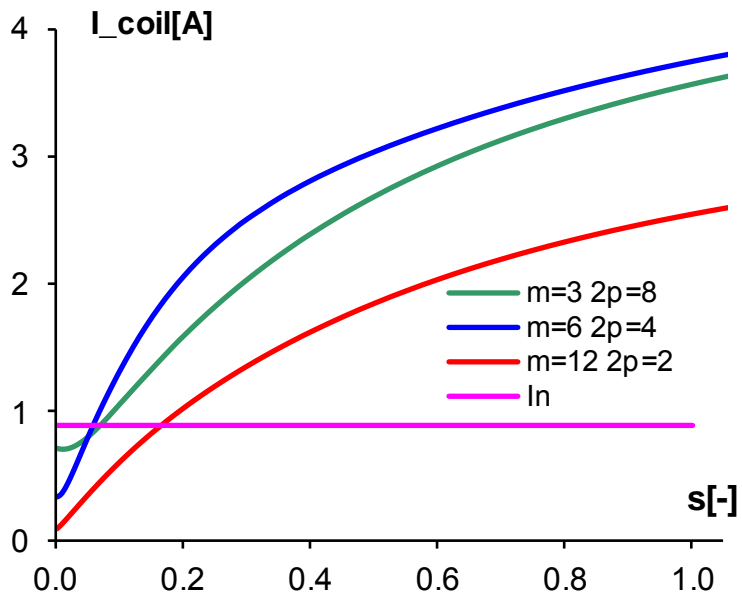

Fig. 7. Absorbed current per coil vs. slip characteristics of the TSSCIM for various no. of poles/phases, operating as motor.

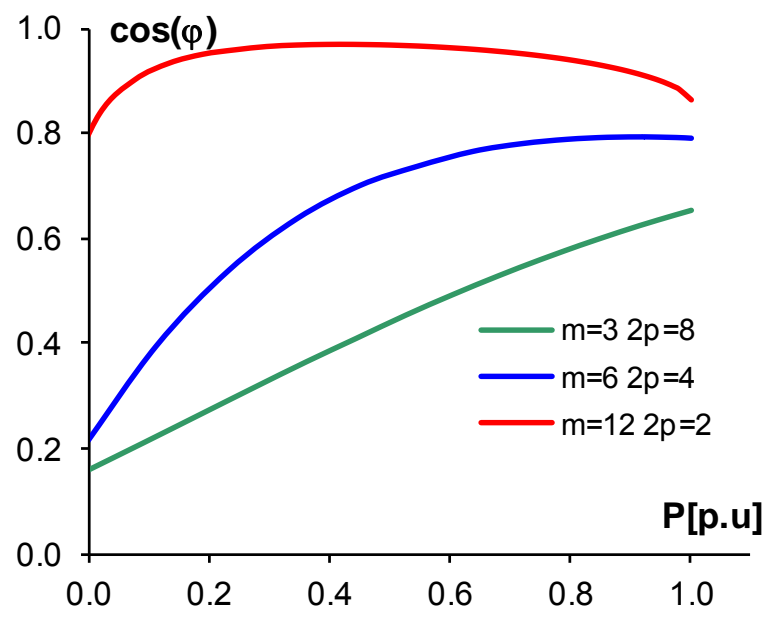

Fig. 8. Power factor vs. output power characteristics of the TSSCIM for various no. of poles/phases, operating as motor.

The variation of the absorbed current per coil with the motor slip and the variation of the power factor with the output power are presented in Figs. 7 and 8 for all the three phase/pole combinations of the TSSCIM, operating as motor. The magenta curve shown in Fig. 7 represents the rated current per coil, having the same value for all the studied cases.

We can notice that the no load current in Fig. 7 increases with the number of poles and the largest start current is obtained for the six-pole machine. Fig. 8 shows that the power factor is the highest for $2 \mathrm{p}=2$ and the lowest for $2 \mathrm{p}=8$.

The torque-slip characteristics of the TSSCIM when operating as generator (i.e. negative slip values) are presented in Fig. 9. A machine with such characteristics may be attractive for wind turbines. By operating at several speeds the TSSCIM can be an interesting solution to harness more energy from the wind than a classical single speed induction generator.

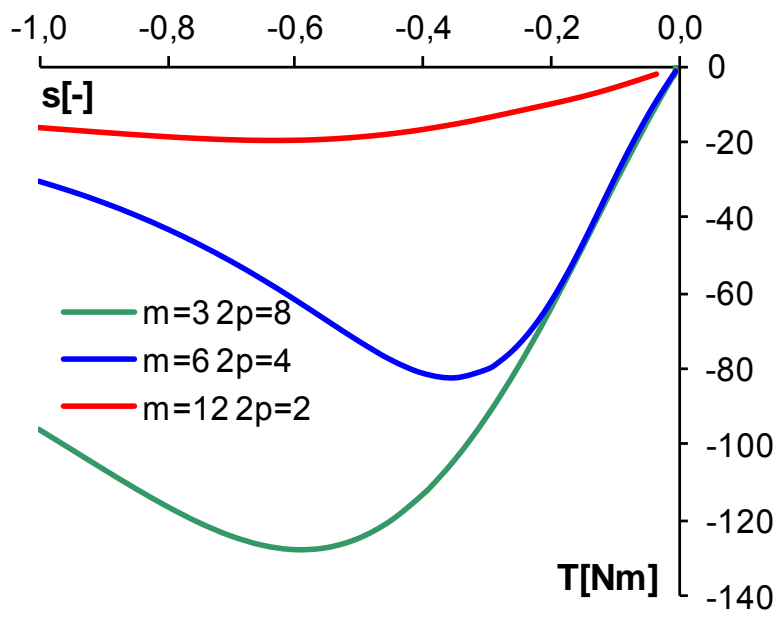

Fig. 9. Torque-slip characteristics of the TSSCIM for various no. of poles/phases, operating as generator. 
We can notice that the pull-out torque in case of generator operation of TSSCIM, Fig. 9, is much larger than in case of motor operation, Fig. 5.

Another important performance criterion of the TSSCIM numerically evaluated in the paper is the machine efficiency defined by the relationship:

$$
\eta=P_{2} / P_{1}
$$

where $P_{1}$ is the absorbed power and $P_{2}$ is the useful power delivered by the machine.

In case of motor operation the absorbed power is the active power $P_{1}=m U I \cos \varphi$ where $\mathrm{m}$ is the number of phases, $U$ is the phase voltage, $I$ is the phase current and $\cos \varphi$ is the power factor and the output power $P_{2}$ is a mechanical power $\mathrm{P}_{2}=T \Omega$ where $T$ is the mechanical output torque and $\Omega$ is the rotor angular speed. In case of generator operation the absorbed power $P_{1}$ is the mechanical power received from the prime mover and the output power $P_{2}$ is the electrical power delivered to the grid.

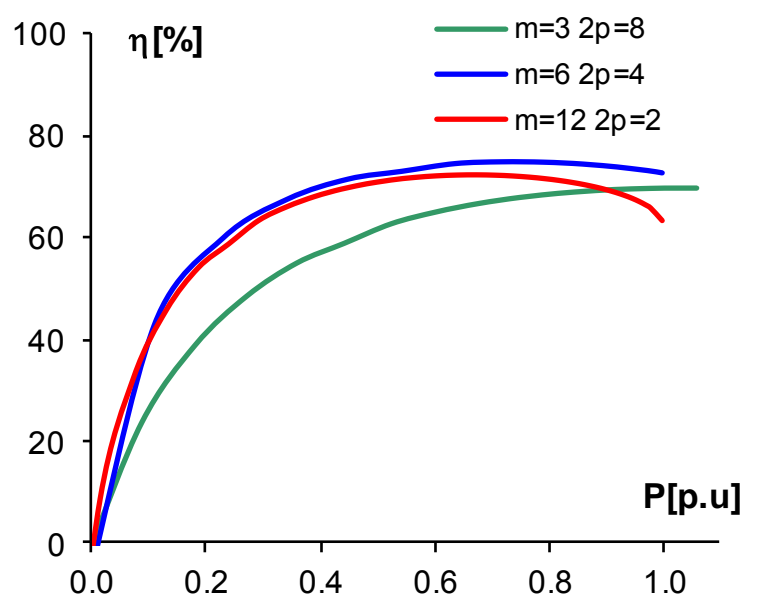

Fig. 10. Efficiency curves TSSCIM for various no. of poles/phases operating as motor.

The efficiency curves of the TSSCIM operating as motor presented in Fig. 10 show that the most efficient machine for a wide load range is that with 4 poles.

\section{Conclusion}

The numerical analysis presented in the paper proved to be useful for the evaluation of the steady-state load capability of the TSSCIM for three different pole/phase arrangements ( 2 poles/12 phase, 4 poles/ 6 phases and 8 poles $/ 3$ phases) using the same stator windings.

The numerical results prove that the machine is well designed from magnetic point of view, the magnetic flux density being kept within reasonable limits for all the proposed stator windings arrangements, Fig. 4.

In case of larger number of poles the pull-out torque of the machine increases both as motor and generator making it suitable for the electric drive of vehicles or for wind turbines.

At a first sight we can state that the operation characteristics of the studied motor are not spectacular but we have to keep in mind that the investigation was done starting from a series induction motor. If the initial machine with large number of poles were designed by neglecting the constraints related to the overall size and ventilation we could obtain a higher efficiency machine.

The paper shows also that by the proposed solution we can control the TSSCIM speed in a wide range, 4:1, with superior electrical and operation characteristics.

If we double the synchronous speed of TSSCIM by changing the number of phases we obtain a reduction with only $50 \%$ of the pull-out torque while if we double the speed by increasing the supply frequency the pull-out torque decreases about 4 times.

If the TSSCIM operates at small loads we can use pole/phase arrangements with superior operation characteristics.

\section{Acknowledgement}

The work has been co-funded by the Sectoral Operational Programme Human Resources Development 2007-2013 of the Romanian Ministry of Labour, Family and Social Protection through the Financial Agreement POSDRU/89/1.5/S/62557.

\section{References}

[1] L. Melcescu, M.V. Cistelecan, O. Craiu, H.B. Cosan, "A New 4/6 Pole-Changing Double Layer Winding for Three Phase Electrical Machines", in Proc. of ICEM 2010 Conference, pp 1 - 6.

[2] O. Ojo, Z. Wu, "Speed Control of a Dual Stator Winding Induction Machine", in Proc. of IEEE Applied Power Electronics Conference, APEC 2007, pp 229- 235.

[3] A. Boglietti, P. Ferraris, M. Lazzari, M. Pastorelli, "Influence of the Inverter Characteristics on the Iron Losses in PWM Inverter-Fed Induction Motors", in IEEE Trans. on Industry Applications, Vol. 32, No. 5, pp 1190 - 1194, 1996.

[4] K. Nagayama et al, "Pole Change Induction Motor and Control Apparatus and Method for the Same, US Patent No. 6,008,616.

[5] E. Muljadi, C.P. Butterfield, D. Handman, "Dual-Speed Wind Turbine Generation", AYEA Windpower '96 Denver, Colorado, June 23-27, 1996.

[6] ***, "Flux 10. User's Guide. Vol. 3. Physical applications: Magnetic, Electric, Thermal”, CEDRAT, 2007. 